\title{
IMPROVING OUTCOMES FOR YOUTH IN TRANSITION
}

\author{
Miriam J. Landsman \\ University of Iowa, School of Social Work \\ Lisa D'Aunno \\ University of Iowa, School of Social Work
}

Acknowledgement: This study was funded by a federal training grant to the first author from the U.S. DHHS, Administration for Children, Youth and Families, Children's Bureau, CFDA \# 90CW1133. Comments concerning this manuscript should be directed to miriam-landsman@uiowa.edu.

\section{Conceptual Base}

The needs of older youth, especially those who are transitioning from foster care to independence and adulthood, are only recently being seriously addressed by child welfare services. This is in response to startling statistics on the number of youth who age out of foster care; more than 26,000 youth existed foster care in 2006 through" "emancipation" (U.S.DHHS, 2008). The child welfare system has long focused its limited resources both on the "front end" (child protective assessment/ investigation) as well as on the youngest and seemingly most vulnerable children. However, there is ample evidence to suggest that youth who enter adulthood by aging out of child welfare services are equally vulnerable, though in different ways. Relative to their peers who grow up in stable homes, youth who age out of foster care are disadvantaged economically, socially, emotionally, and physically.

The myriad of issues facing youth who "age out" of foster care are often portrayed in grim terms. We know that these youth are usually financially destitute and with limited human capital in terms of employment skills, or educational attainment (Blome, 1996), and are usually without safe and/or stable housing (Courtney et al., 2001). Because most of these youth did not have permanency resolution, they often lack positive support from family and peers, even though many return to their families-of-origin in which the youth experienced maltreatment. We also know that many older youth in care have been identified with special medical, emotional, behavioral, and developmental issues (Wattenberg et al., 2001). A higher proportion of youth from the foster care population compared to the general population become involved in the criminal justice system (Courtney at al., 2001) and they are more likely than their peers to experience pregnancy and parenting at young ages (Nollan et al., 2000). Furthermore older youth in care are disproportionately members of racial and ethnic minorities (Adler, 2001; Kemp \& Bodony, 2000; Davis, 1992; Curtis \& Denby, 2004), and may face additional problems due to discrimination in employment, housing, and other areas.

As part of the Chapin Hall Center for Children, University of Chicago's Mid- 
west Evaluation of the Adult Functioning of Former Foster Youth, relatively current data are available on former foster youth in Iowa. The picture that is presented is a profile of youth who have experienced child maltreatment, often of multiple types, youth who have experienced multiple placements and re-entries into care, as well as histories of running away from placements (Chapin Hall Center for Children, 2005). This study also documents a higher propensity for experiencing grade retention, suspension, and expulsion from school, involvement with the juvenile justice system, being a victim of violence, and needing mental health services among older youth in care.Yet, interviews conducted with these youth suggest a remarkable level of satisfaction with their care and with their relationships with family members, both foster and biological, as well as fairly strong levels of social support. Ninetypercent of former foster youth interviewed reported being optimistic about the future (Chapin Hall Center for Children, 2005).

If one looks at older youth in care solely from a problem-focused perspective, it soon becomes overwhelming. While not denying that youth aging out of foster care face many hurdles to economic, social, and emotional well-being, a positive youth development approach that recognizes the strengths and capacities of each youth in the context of cultural factors and needs, that seeks to build permanent connections and supports with the youth, and that engages a larger community as collaborative partners, offers a path to a more promising future than leaving the youth on his or her own at the legal age of 18.

The needs of older youth in care were recognized in the Foster Care Independence Act of 1999, and now long overdue efforts are underway at federal and state levels to address the unique needs of older youth in transition. For the past three years, the University of Iowa, School of Social Work (UI) and the Iowa Department of Human Services (IDHS) have been collaborating on a federally funded grant to improve outcomes for youth in transition from foster care to adulthood through training of public child welfare supervisors, workers, and community partners. The purpose of this article is to describe the process of developing, implementing, and evaluating this statewide training effort.

Our project was based on the key assumption that supervision is a specific area of practice with its own skill sets. Therefore supervisor training should include both content in the core principles of transition planning, as well as the skills for supervising caseworkers in the work of transition planning. As coaches, teachers, and mentors for their staff, public child welfare supervisors must themselves understand the needs of youth in transition, successful strategies for engaging youth from a positive youth development framework, the importance of permanent connections, and evidence-based interventions with older youth. Supervisors must also learn and model culturally competent practice, as well as practice in ways that involve collaboration with the multitude of individuals and community entities that work with older youth both formally and informally.

We conceptualized this project as a multi-level training, beginning with build- 
ing knowledge and skills for supervisors, then moving to the next step of training caseworkers, with supervisors as co-facilitators. Iowa's public child welfare workforce is small, with approximately 115 supervisors and 750 caseworkers statewide. Training at both levels had the advantage of providing consistent content, and including supervisors as co-facilitators would help to reinforce their roles as coaches and mentors. There are also ten transitional planning specialists around the state; these individuals, as well as the state's transition planning program manager, were heavily involved in developing and implementing the training.

Originally we had intended to conclude the project with a statewide training to which a variety of provider agencies would be invited. However, during the course of implementation, we realized that many of the complexities around transition planning have to do with local systems. Therefore, we reconfigured the statewide roll-out as a series of localized events. Instead of hosting only one statewide training, we implemented a community day in each of the state's eight service areas. Supervisors and mid-managers in each service area shaped the format and content of that community day, based on local needs. Throughout the development and implementation of this project we have also kept the core principles for transition planning, positive youth development, cultural competence, collaboration, and permanent connections, at the forefront. These principles are discussed further under training content.

\section{Supervisory Curriculum Development}

At the time we began this project, UI and IDHS had been developing and implementing a statewide training program for Iowa's supervisors and mid-managers as part of a federal grant on improving recruitment and retention in public child welfare. The focus on supervision was based on a substantial body of research demonstrating the importance of supervision and supervisory support in promoting job satisfaction and retention of child welfare employees (Curry, D., McCarragher, T., \& Dellmann-Jenkins, M., 2005; Dickinson \& Perry, 2002; Landsman, 2001; Mor Barak, Levin, Nissly, \& Lane, 2006; Rycraft, 1994). The multi-phased supervisory curriculum was designed to engage supervisors at all career stages in honing skills as reflective practitioners in organizational leadership and supervision. We envisioned the transition project as complementary to the work in progress, permitting a special focus on developing supervisory skills in this content area.

The supervisory curriculum provides theoretical foundation, concrete application, and emphasis on the improvement of client outcomes through enhanced organizational effectiveness. Material is presented in the context of a comprehensive model of child welfare supervision. This includes acknowledging the various roles of the supervisor in the unit (administration, education, consultation, counseling, and evaluation), the contextual factors influencing supervision (e.g., law, policy, economic conditions, and political realities), and the role of the supervisor in the organization (advocating for resources for staff and clients, negotiating relationships 
with community providers, and responding to client and community concerns).

Our approach to curriculum development is based on sound principles of adult learning, emphasizing practical application of useful concepts and best practices, using case-based applications, and providing adequate time for collegial interaction. The training integrates measurable outcomes and learning objectives and supports the IDHS practice model and redesign initiatives. Supervisors are provided tools for self-assessment of their own supervisory behaviors as well as detailed task analyses of worker competencies which can help them develop individual and unit plans with their staff. We have also developed easy to use resources to share with staff and provide supplemental reference materials and web-based resources for use in direct on-the-job application.

Curriculum development occurred through a process of gathering information and collaborating with a variety of stakeholders. At the beginning of the project we convened an advisory committee, which has continued to meet and provide feedback on a monthly basis over the three years. The advisory committee encompasses the IDHS training committee which oversees all child welfare training for the state. We added two transition planning specialists and two project consultants who work with Iowa's youth initiatives to this committee. Combining our project advisory committee with the state's child welfare training committee helped to ensure that our training would be consistent with and supportive of other IDHS initiatives.

In preparation for developing supervisor training that would be responsive to Iowa's needs, we conducted a series of focus groups in each of the eight service areas around the state with IDHS supervisors, seeking input from as many supervisors as possible. In addition, we conducted focus groups with caseworkers in rural and urban areas, with a small group of IDHS social workers called transition planning specialists, with youth who had recently aged out of foster care, with Native American families, with and providers of aftercare services for youth in care. We also conducted interviews with key informants representing foster parents, public health, IDHS administration, advocacy organizations, and organizations serving primarily minority youth and families.

In addition to gathering information though focus groups and interviews, we conducted a systematic review and analysis of the content of the twelve independent living curricula for caseworkers developed by Children's Bureau grantees. This activity was accomplished in collaboration with the University of Louisville. A matrix summarizing key elements of each curriculum, organized according the four core principles of transition planning, was used in specifying competencies for supervisors and caseworkers and in curriculum development.

Information from the focus groups, interviews, and review of independent living curricula were all used to inform the development of competencies for supervisors and a complementary set of competencies for caseworkers. We shared these with the project advisory committee and revised them in accordance with feedback. The competencies, used in guiding curriculum development, focus on improving 
practice with youth in transition by promoting stronger youth involvement in case planning and decision-making; engaging a youth-centered team for strengthening the youth's permanent social or family-like connections and providing support for life skill development; approaching the youth's preparation for adulthood from a positive youth development perspective; understanding the youth's cultural heritage and incorporating this in transition planning; strengthening collaboration among the various entities involved in transition planning and support; and addressing the complex needs of youth.

Our multiple information gathering activities enabled us to better focus the content and approach of the training curriculum while attending to the original goal of addressing the four core substantive areas. For example, while we proposed a round of supervisor-to-worker trainings, the widespread concern about the need for better community collaboration led us to develop a regional approach and to include community partners in the second day of regional training. Another example of how the training was informed by the focus group research is the inclusion of youth voices throughout the curriculum. Two young adults, one who had aged out of foster care and another who was adopted as a teen, serve as curriculum advisors; one of these advisors attends each training session as a resource and co-facilitator. Youth panelists from the statewide foster care youth group called Elevate present their perspectives at the closing session of each training. Throughout the two-day training, youth perspectives are presented through multi-media such as video, photography and quotes from the youth focus groups which appear on PowerPoint. Elevate staff and participants developed a music video for the section on permanent connections, presenting their songs and poetry about dislocation and multiple moves, fear of attaching to a new family, grief over the loss of sibling connections, and hope for reconnection and success (Elevate, 2007).

In implementing the training, we divided the supervisors into four groups, mixed geographically in order to provide opportunities to meet with others across the state. The training was provided in two-day sessions in Des Moines, the most central location. The first training also served as a pilot, with revisions made according to consumer and trainer feedback.

\section{Curriculum Development for Regional Trainings}

Following training of supervisors, we turned our attention to the caseworker and community trainings to be held in each service area. Due to variation across service areas in how community agencies were working together, and because we wanted to create opportunities for IDHS supervisors to take visible leadership roles, we decided to offer community trainings in each of the eight service areas and involve supervisors in planning and hosting the events. To maximize efficiency, the community training was scheduled the day after the worker training at the same location whenever possible.

Planning for the caseworker and community trainings began on the second day 
of each of the four statewide supervisor trainings. Supervisors from the same service area worked in teams to complete a planning questionnaire for the community rollout, recommending goals for the community day, suggesting topics for training and facilitated discussion, and drafting a suggested invitation list. Supervisors were also invited to volunteer for a planning committee if they so desired. After completion of the statewide supervisor trainings, we compiled results for each service area and contacted the eight service area managers (top regional administrators) asking them to appoint a planning committee. Our suggestion was that each committee include one social work administrator (supervisor of front line supervisors), the IDHS community liaison, the transition planning specialist, and some or all of the supervisor volunteers. Our recommendations were accepted, and some service area managers chose to add to the basic committee a decategorization coordinator, a juvenile court officer, and/or facilitators of the local Elevate (foster youth) chapter.

The UI team of co-trainers and a consultant hired to manage coordination for the rollouts, traveled to each service area and met with the eight planning teams, reviewing recommendations made by the supervisors and discussing the best way to approach the community rollout. Questions guiding the discussion included: 1) Where is your service area currently in terms of community collaboration to improve outcomes for youth in transition?; 2) Where do you want to be a year from now? What are your priorities?; 3) How could training and/or resources help?; 4) Who do you need to have at the community day to make that happen?; 5) What would constitute success for a day of training?; 6) What kind of preparation would need to be done to facilitate a successful day?; and 7) How should youth be involved?

We offered the committees options about the length of the training day (which usually depended on the target audience and travel times), the relative proportion of the day to be spent on training and facilitated discussion, and the number of topics to be addressed. Each planning committee was responsible for managing invitations and replies. All eight areas invited the representatives of their legislatively created transition review committees, and all eight areas are also invited a panel of former foster youth to talk about what has made a difference to them in their own transitions. Most service areas included providers under contract to IDHS to provide transition services. Three service areas invited judges, attorneys, and juvenile court officers, and one area reached out to voluntary organizations such as the Salvation Army and local church congregations. Educators and visiting nurse associations were also on many invitation lists. The content of the community training is discussed further later in this article.

A similar planning process was used for the worker training. We asked supervisors to review the content of their two-day training and recommend which topics would be most useful for a one-day worker training. While engaging all of the supervisors in this initial process, we emphasized the importance of their role in coaching and reinforcing best practice. When we met with the regional planning committees, we proposed a full-day training, but offered some options about the 
relative emphasis on training topics and offered some workshop options to allow for worker choice. We also gave the committees the choice about whether to involve child protective assessment workers in the training; all decided not to include the assessors but one committee asked that we work with them to create a half-day training for assessors. The committees were very engaged in thinking about how best to use the day. All of the committees decided to include a youth panel.

\section{Supervisor Training Content}

The supervisor training is delivered in two full consecutive days of training. We begin with a review of the model of supervision that we had developed through the Recruitment and Retention project, showing where the transition training fit into the larger structure of supervision practice. We then present to the supervisors what we had learned our focus groups, key informant interviews, and recent research from national data and Iowa's population of youth aging out of care. This information is used to "make the case" for improving the quality of service to older youth in the child welfare system.

\section{Key "Youth in Transition" Curriculum Concepts for Supervisors}

\section{Start Early.}

Though Iowa law does not mandate transition planning until the youth's sixteenth birthday, our training emphasized that youth participation in case planning should begin much earlier. Formal tools for assessing a young person's life skills, such as the Ansell-Casey Life Skills Assessment, can be used with youth beginning at age 14 . Giving youth choices, treating them as resources and partners for generating solutions to problems, assuring their attendance at court hearings, and informing youth about their family's progress are elements of youth participation which can be implemented for younger youth in care, and certainly for preteens and teens. Youth who have had every important decision made for them by a government agency without their participation are ill-equipped to face the challenges of adulthood.

\section{Incorporate Positive Youth Development into Supervision and Case Planning.}

Positive youth development (PYD) approaches focus on the whole child and highlight the achievement of developmental tasks, concentrating on interactions with family, school, neighborhood, societal, and cultural contexts (Catalano et al., 2002). PYD stems from positive psychology, which focuses on the development of positive qualities in youth such as competence, optimism, compassion, and other strengths. Positive psychology downplays the notion that youth misbehave because they are in some way damaged, or defective, and in need of repair, while focusing attention on responses to the absence of contentment, common sense, and other positive qualities of healthy child development (Kelley, 2003). 
A core tenet in PYD is that young people are the primary agents in their own developmental process seeking ways to meet their basic physical, emotional, spiritual, and social needs and to build competencies and connections they perceive as necessary for survival and success (AED/Center for Youth Development and Policy Research, 1996). The PYD approach sees youth as resources rather than problems. All youth have talents, energies, strengths and constructive interests that can be used to facilitate their acquisition of competence and the capacity to contribute to the world (Damon, 2004).

The second tenet of PYD is that the role of youth helpers (e.g., other people, organizations, and institutions) is to promote positive development through providing opportunities and supports. The typical inclination of caregivers and educators is to do things "to" and "for" youth rather than "with" them. The insight of positive youth development (PYD) is that young people thrive when adults listen to them, respect them, and engage with them in meaningful investments in the community (Nicholson, Collins, \& Holmer, 2004).

A significant challenge to incorporating the positive youth development approach in public child welfare practice is transforming a traditionally problemfocused system into one that is built on recognizing and working from strengths. While "strength-based" language is now pervasive in child welfare, this approach is not always evident in practice. Child welfare workers are accustomed to viewing older youth in care as burdened with problems, whether a result of lengthy placement histories, years of maltreatment, behavioral and emotional problems, inability to be adopted, or placement instability. A positive youth development approach requires a profound change in the way that older youth are viewed and in intervention strategies to help youth become successful.

In training, supervisors make the connection between the child welfare field's focus of safety, permanency, and well-being and the twelve desired outcomes in positive youth development: physical health; mental health; intellectual ability; employability; civic; social and cultural ability; safety; self-worth; belonging/membership; responsibility/autonomy; mastery; and spirituality/self awareness (AED/Center for Youth Development and Policy Research, 1996).

Supervisors consider how they, with their workers, can help youth in care to access necessary opportunities for positive development-opportunities for expression and creativity; group membership; part-time paid employment; contribution service and exploration; practice; and reflection. Supervisors discuss how best to assure that youth in care have relationships with adults that will provide high expectations; standards and boundaries; nurturance and friendship; connections to important resources; and strategic support-assistance in planning and assessing their options, motivating, and coaching. The role of the caseworker is carefully considered - how the worker approaches interactions with the youth, using an adaptation of Lofquist and Miller's (1989) Object/Recipient/Resource framework: what kinds of direct support workers can provide, and how workers can recruit others to 
engage with the youth. The opportunity to share perspectives with other supervisors has proven especially helpful. During one training session a supervisor stated "when making case transfers, I give top priority to maintaining older youths' relationships with their worker."

\section{Promote Culturally Responsive Practice with Older Youth in Care.}

In a two-day training it is impossible to adequately address all of the cultural issues for foster youth. We decided to frame the inquiry in terms of the adolescent's development of social and cultural identity, with the added challenge that youth in out of home care must often undertake this task apart from their families, cultures, and communities. To stimulate conversation, we view two videos, Knowing Who You Are (Casey Family Programs, 2005) and vignettes from Breaking the Silence: LGBTQ Foster Youth Tell Their Stories (National Center for Lesbian Rights, 2005). Supervisors draw lessons from the videos, primarily about the importance of their workers listening to and engaging youth in conversations about culture and identity. Supervisors discuss strategies for increasing workers' cultural competence and ways to find mentors and other cultural opportunities for youth of color. They consider ways to assure that LGBTQ youth feel safe to disclose to the agency their sexual orientation, gender identity, and problems with victimization such as harassment or bullying at school. We also examine family-centered approaches to working with those who have rejected youth based on sexual orientation or gender identity.

\section{Build and Sustain Permanent Connections.}

Research has documented the tendency for youth who age out of care without achieving permanency to return to their families of origin (Courtney \& Barth, 1996; Landsman et al., 1999; Mallon, 1998; McMillen \& Tucker, 1999; Westat, 1991). For older youth who are unable to be reunified with their own families and who have not achieved another permanent home through adoption or guardianship, child welfare has begun to expand its definition of permanency to include "relational" permanency, that is, helping youth establish "enduring family relationships that provide for physical, emotional, social, cognitive, and spiritual well-being" (Frey et al., 2005). "Permanent connections" are those with whom the youth has some emotional attachment-birth family, extended family, kin, foster family, mentors, etc.and who can be expected to provide lifelong support. Establishing permanent connections is key to helping youth sustain support systems as they enter adulthood.

Best practice points to blending the goals of exploring permanency and helping the young person develop life skills using a youth-centered team. Where older youth are concerned, the youth-centered approach places the youth at the helm of planning for her/his future, with support from family, kin, and other individuals who play a key role in the youth's life. For older youth who are approaching adulthood without having had permanency resolution, supporting their capacity for self-determination is critical for their successful transition. The youth-centered 
team composed of the youth, the worker, and the significant adults in the youth's life, meets regularly to"explore and support the highest level of commitment that each adult can make as a permanent parent or extended family member" and to develop a comprehensive case plan that addresses the youth's current needs and future hopes and plans (Frey, 2007). The youth's needs for permanent connections and to acquire life skills are integrated by recruiting adults in the youth's social network to support the youth in skill development (e.g., teaching the youth to drive or cook) and to offer various forms of material, emotional, and strategic support for the attainment of the youth's goals (e.g., career exploration, college applications). (Frey, 2007).

Training activities around youth permanency include using materials to build "models" of permanency and the introduction of a variety of tools to assist workers in talking with youth about permanency and identifying potential permanent connections. Small group work with brief case scenarios gives supervisors an opportunity to consider the potential utility of these tools in practice.

Youth permanency is a multifaceted construct which includes legal status, stability and appropriateness of the youth's placement setting, connectedness to family and significant others, and the youth's emotional well-being (Landsman et al., 1999). The curriculum presents research and best practice for maintaining placement stability, including providing more intensive support (e.g., worker visits, therapeutic support) for the youth and foster parents in the youth's first six months of placement.

\section{Develop Community Collaboration for Youth in Transition.}

The literature on interagency collaboration identifies a set of characteristic dimensions: stakeholder involvement, shared goals, responsibilities, rewards, resources, authority/decision-making, evaluation, structures, and vision/values (Austin, 1997; Urwin \& Haynes, 1998; Walter \& Petr, 2000). Each of these dimensions serves to strengthen the structure and the common purpose behind it. Shared vision and values, in particular, are believed to be crucial to successful interagency collaboration (Bailey \& Koney, 1996; Harbert, Finnegan, \& Tyler, 1997; Morgan, 1995). Walter and Petr (2000) describe shared values as the core of the interagency collaboration. These shared values become the guiding force for the collaborative and the basis for the activities that are undertaken. Our training involves guest panelists representing both the public child welfare agency and community-based agencies in rural and urban settings, with a focus on what is working well and the role of the public agency in improving collaboration. The panel presentation leads to a discussion among the supervisors about strategies for strengthening existing structures for collaboration, including legally mandated transition plan review teams and Iowa DHS community partnership initiatives. The supervisors work in small groups to share ideas on common challenges in their local collaborative efforts, such as building a shared vision and making their collaborations more culturally diverse. 


\section{Content of Regional Trainings}

Most of the service areas identified a specific focus for their community day. For some it has been increasing community and provider participation in youth centered team meetings. For others it is communicating to their community partners how IDHS is working to meet its responsibilities to transitioning youth, combined with an invitation for closer collaboration. For the service area focusing on voluntary organizations, the goal is to educate those organizations on the resources available to youth who age out. At each community training, we have provided data presentations on outcomes of concern for area youth in transition.

During the development of the supervisory curriculum we had worked with two creative transition planning specialists who developed tools to help workers track the transition planning process, understand the available resources for transitioning youth, and how to access them. We had also developed a presentation and materials on how to make better use of the Ansell-Casey Life Skills Assessment in transition planning. The local planning committees felt it was very important to give their local transition planning specialists the opportunity to be seen as leaders and experts in their regions. In response, we met with the transition planning specialists, invited them to present and reviewed our materials. The result was another transition planning specialist creating an even richer presentation which was used by his peers. Participants rated the resource presentation among the most useful portions of the training content. The process of each transitional planning specialist "owning" the work was an important benefit of the regional approach.

We felt that the presence of supervisors at the community training was a critical component, so we worked very hard to secure their attendance and to offer them visible roles during the day, including welcoming participants, offering introductory remarks, and leading table discussions. The interactive nature of the day allowed for supervisors to show their leadership through skillful discussion of the topics.

A variety of training methods were used, including short PowerPoint presentations, large group and small group discussions, and videos. A key goal was infusing the training with the voices of youth, which we did in a variety of ways, including presentations by youth, incorporating comments from the focus groups with youth into the presentations and training manual, and using a variety of videos, including a music video created by Elevate specifically for our training.

Most of the planning committees asked that we save time at the end of the day for community attendees to make "commitments" about how what they intended to implement in their individual practice and what they intended to take back to share with their agencies. Those commitments were memorialized in a variety of ways. In one area, the workers in their training the previous day created paper dolls signifying a youth in care with whom they were working. The dolls were on display at the community training, and community participants were asked to write their commitments on paper umbrellas which were then attached to the hands of the paper youth. This idea was generated by the local planning team. 


\section{Content of Worker Training}

Caseworker training was provided in a one-day session in each of the eight service areas, and focused on the four core content areas. Workers were asked to bring information about one older youth to the training, to help make the content more relevant for them. One particularly useful part of the training included introducing a variety of tools for identifying permanent connections. Workers had opportunities to review each tool and to talk with each other and with their supervisor about how they might apply these tools in practice.

We knew from the focus groups that we needed to address the challenges of transitioning special needs youth into the adult mental health system; because of a wide variation in practice across the state we decided to accomplish this at the regional level. We recruited the two IDHS staff who work with the county Central Point of Coordination (CPC) staff to transition youth into adult services. They offered a 75 minute workshop on the process, and invited local county CPCs to join them in the presentation. This was a great plan, as it engaged these individuals in the community day and encouraged them to make public commitments to collaborate. Several CPCs participated in the entire community day.

A key component of the grant is strengthening the supervisors' role in training their workers. We approached this in several different ways. First, we created a set of supervisory tools for the supervisors to use in their administrative, education, consultative, and evaluative functions. Second, we gathered a variety of training resources for supervisors to use in unit meetings. Third, we recruited supervisors as hosts for the worker training, to sit with their teams during the training, and to facilitate table discussions. We provided the supervisors with prepared discussion questions for the cultural competence portion of the training. We also provided the workers with a set of practice tools in their participant's manual.

By engaging supervisors in planning and implementing workers' training and providing workers with an introduction to best practices, we supported and empowered the supervisors to lead their teams to improve outcomes for youth in transition. The trainers noted informally that workers appeared much more engaged in training when supervisors modeled that engagement and enthusiasm.

\section{Barriers and Facilitators}

One of the challenges to our project has been implementing a statewide training that also takes into consideration the differences by locality. Iowa's 99 counties are organized into eight service areas, and some of these service areas are predominantly urban or rural. There are often vast discrepancies in resources and services available in rural counties compared to urban areas, a fact that we had to keep in mind as we developed the curriculum. In addition, supervisors in rural areas typically supervise multiple counties, thus having less face-to-face supervision time. Finally, some areas were already further along in thinking about transition planning than others, and we had to find ways to capture the best of current practices while re- 
maining sensitive to the variation across the state in the area of transition planning.

Another significant challenge to implementing our project has been the almost continual changes that have occurred within IDHS during the same three-year period. In implementing a new Model of Child Welfare Practice, IDHS had renegotiated its contractual services, which also affected the way that supervisors and caseworkers were viewing their own jobs. Our training team had to stay on top of these changes to make sure that the training was consistent with "current" practice. Having the IDHS training committee as our advisory committee was helpful in this regard, alerting us to imminent changes.

Our project has benefited from some facilitative factors as well. One such factor is that Iowa's foster youth group, Elevate, was available to work as part of our team and to assist with our training efforts, including our regional trainings around the state. Having a youth presence at the trainings was very important to maintaining the primacy of the positive youth development framework.

In addition, we have observed that over the three years of this project, considerably more attention is being paid to the population of older youth in care. When we began this effort, it was sometimes a struggle to engage training participants in addressing the needs of this population. However, over time more resources and initiatives addressing the needs of older youth have been developed, and CFSR outcomes will now be addressing older youth. These factors have reduced our need to "sell" the importance of transition planning for youth aging out of foster care, as we had to do early on. Of course, we like to think that our efforts have played a role in bringing this increased focus on youth aging out of foster care.

The fact that we had already developed a collaborative relationship with IDHS supervisors through our Recruitment and Retention project also helped to facilitate the transition training project. We have been able to build on the supervision practice model with a specific focusing on the unique content of transition. With this foundation, we have also able to train and support the local leadership role of those who supervise the work of transition planning, as well as to train the caseworkers and community partners who work directly with transitioning youth.

\section{Project Evaluation}

Both processes and outcomes are being evaluated in this project. The process evaluation has examined issues related to implementation, such as timely completion of project activities and extent of participation in trainings by supervisors, caseworkers, and youth. The outcome evaluation focuses on the extent to which the desired results are achieved, and we have identified short-term, intermediate, and long-term outcomes by which to evaluate this project's effectiveness.

Short-term outcomes include satisfaction with training content/perceived usefulness of the training, and increased knowledge of transition planning and core principles by supervisors and caseworkers from pre- to post-training. Consumer satisfaction has been measured through surveys distributed at the conclusion of 
each training session, with feedback used in revisions of the training content and methods. To assess knowledge gain, we developed tests and administered them prior to the training and at the end of the training. We conducted item analyses and revised the test questions to eliminate items that performed poorly.

The key intermediate outcomes identified and measured in this project are utilization of knowledge and skills by supervisors in their supervision practice and improved transition planning based on the core principles discussed earlier. Utilization of knowledge and skills is being assessed through supervisor self-reports on their own supervision practice over time, using a behavioral assessment measure developed for this project. Originally we had planned to use a similar assessment for workers, but with only one measurement opportunity we decided that it would not be useful to attempt to track this information longitudinally with all public child welfare caseworkers. With regard to the intermediate outcome of improved transition planning, this is being assessed through a cohort study described later in this section.

Longer-term outcomes for this project include those that we envision occurring beyond the funding period of this grant. One such outcome is the incorporation of transition training in the IDHS training plan. The UI will be available to continue to provide this training to public child welfare supervisors and caseworkers beyond the funding period. A second long-term outcome, the integration of the training content in UI child welfare curricula, has already been achieved—we have included transition as a unique topic in the School of Social Work's course on child welfare policy and practice. The ultimate long-term outcome, improved well-being for youth in transition out of care, will need to be assessed over time.

As noted previously, the intermediate outcome of improved transition planning is being evaluated through a cohort study of transition planning prior to and following training, using interviews with youth who are nearing the age of 18 , and with the youth's permission, an interview with the caseworker as well. The focus of the interview is on planning for the transition process. Issues assessed from both perspectives include: whether permanency goals are better articulated after the training, whether there is evidence that youth are playing a stronger role in their transitional planning, the extent to which permanent connections are being pursued and implemented, whether an appropriate array of services, as well as informal supports, are being identified and coordinated. The working hypothesis is that transition planning from pre-training to post-training will demonstrate greater youth involvement, attention to cultural needs, collaboration with community entities, and strengthened permanent connections. We did not ask questions about the youth's child welfare history, risk factors, and behaviors; rather we asked about the youth's plans for turning 18, the youth's role in transition planning, and what steps had been taken toward the transition process. Nevertheless, this study took close to year to receive approval by the Institutional Review Board, primarily because we were requesting a waiver of parental consent to participate in the interview. 
The first cohort of youth was identified prior to conducting the first supervisor training. We used stratified random sampling to select 12 youth from each of the state's eight service areas who were between the ages of 17.3 and 17.9, who did not have a diagnosis of mental retardation, and who were not residing in a juvenile detention facility. The latter two criteria were established to ensure that the youth was capable of giving informed consent and without coercion. We sent a letter to each of the 96 youth explaining the study and letting them know that a researcher would be following up by telephone to provide more information and to find out if the youth was interested in participating in the study. We prepared a script for the follow-up phone calls to cover all aspects of the study procedures and to make sure that the youth understood the concepts of voluntary participation and informed consent. For those who agreed to participate in the interview, a time and place for the interview were arranged. The interviewer made an additional contact prior to the agreed upon time to confirm the appointment. During the face-to-face interview, written informed consent was obtained, and the interviews were audio-taped with the youth's permission.

Making contact with the youth turned out to be quite a challenging task. Many of the youth were no longer at their address of record. Some had returned home, several had run from their placement, some had their cases closed, and a couple were in jail. Multiple attempts were made to find every youth, but ultimately out of the 96 youth selected for the original sample, we were able complete interviews with 22 youth and 21 caseworkers (one youth did not give permission to contact the caseworker), representing slightly less than $25 \%$ of the sample. Twelve of the youth interviewed were residing in group homes and ten were living with foster families or relatives.

Now that we are nearing completion of the training, we will be selecting a second stratified sample of youth who are approaching the age of 18 and who meet the other criteria previously noted. Comparing the interview data between the first and second youth cohorts will allow us to evaluate whether transition planning practice has changed after the statewide training effort.

\section{Sustainability}

From the outset we have considered how to sustain training for transition planning after the conclusion of the grant. This is being accomplished through the preparation and dissemination of written curricula, integration of transition content in the UI School of Social Work's child welfare curricula, and the availability of continued training to IDHS and other child welfare agencies through the UI School of Social Work's National Resource Center for Family Centered Practice.

Activities to sustain the work are already in progress. We are preparing written curricula for training public child welfare supervisors to effectively supervise line staff in transition planning for older youth. The curricula will be prepared in print and electronic versions for varied dissemination purposes. Included in these 
curricula are visual PowerPoint presentations that accompany the on-site training. The printed version will be available at cost from the UI and the e-copy by downloading from the website (www.uiowa.edul nrcfcp). An on-line toolkit with resources for supervisors for transitional planning will also be produced and made available to trainees within the Iowa public child welfare system and disseminated nationally.

In order to facilitate sustainability of the training between the UI and IDHS partnership, the curriculum for supervisors and workers will be available on a continuing basis. The training programs will be added to the menu of training programs offered by IDHS, and NRC trainers will be available to conduct new groups on an as-needed basis. Because we were able to train all current supervisors and a large proportion of caseworkers, subsequent trainings will only be necessary for new employees.

We have also integrated the content of transition training into the UI School of Social Work's child welfare curricula for undergraduate and graduate students. A segment of the course, child welfare policy and practice, focuses on the issues of youth in foster care and the transition process. Thus, social work students who are preparing for child welfare careers will receive content that is timely and relevant to working with the youth population.

Our project team is prepared to make this training available to other interested states and communities. Readers who wish to learn more about the training program described in this article should contact the primary author at miriam-landsman@uiowa.edu.

\section{References}

Adler, L. (2001). The meaning of permanence: A critical analysis of the Adoption and Safe Families Act of 1997. Harvard Journal on Legislation, 38, 1.

AED/Center for Youth Development and Policy Research (1996). Advancing Youth Development Curriculum.

Austin, M. (1997). Service integration: Introduction. Administration in Social Work, 21(3/4), 1-7.

Bailey, D., \& Koney, K.M. (1996). Interorganizational community-based collaboratives: A strategic response to shape the social agenda. Social Work, 41(6), 602-611

Blome, W. (1996). What happens to foster kids: Educational experiences of a random sample of foster care youth and a matched group of nonfoster care youth. Child and Adolescent Social Work Journal, 14(1), 41-53. 
Casey Family Programs (2005) Seattle, WA. Knowing who you are. DVD with resource guide. $h$ ttp://www.casey.org/Resources/Projects/REI/KnowingWhoYouAreVideo.htm

Catalano, R. F., Berglund, M. L., Ryan, J. A. M., Lonczak, H. S., \& Hawkins, J. D. (2002). Positive youth development in the United States: Research findings on evaluations of positive youth development programs. American Psychological Association. http://journals.apa.org/prevention/volume5/pre0050015a. html [2003, November].

Chapin Hall Center for Children (2005). Midwest evaluation of the adult functioning of former foster youth, wave 1: Iowa findings. Chicago: University of Chicago.

Courtney, M., \& Barth, R. (1996). Pathways of older adolescents out of foster care: Implications for independent living programs. Social Work, 41(1), 75-183.

Courtney, M., Paliavin, I., Grogan-Taylor, A., \& Nesmith, A. (2001). Foster youth transitions to adulthood: A longitudinal view of youth leaving care. Child Welfare, 80, 685-717.

Curry, D., McCarragher, T., \& Dellmann-Jenkins, M., (2005). Training, transfer, and turnover: Exploring the relationship among transfer of learning factors and staff retention in child welfare. Children and Youth Services Review, 27(8), 931948.

Curtis, C., \& Denby, R. (2004). Impact of the Adoption and Safe Families Act (1997) on families of color: Workers share their thoughts. Families in Society, 85(1), 71-81.

Damon, W. (2004). What is positive youth development? Annals of the American Academy of Political and Social Science, 591, 13-24.

Davis, E. (1992). Wanted: Families to adopt. Black Enterprise, 23(4), 26.

Dickinson, N.S., \& Perry, R.E. (2002). Factors influencing the retention of specially educated public child welfare workers. Journal of Health and Social Policy, 15(3/4), 89-103.

Elevate (2007). Voices of youth. DVD. Words and music by Travis Lloyd Smith and Jewel. Des Moines, IA: Children and Families of Iowa. 
Frey, L. (2007). Transitioning youth: Blending the worlds of permanency and independent living. Voice Magazine, 21-23. Accessed at: http://www.caseyfamilyservices.org/pdfs/casey_transitioning.pdf

Frey, L., Greenblatt, S., \& Brown. J. (2005). A call to action: An integrated approach to youth permanency and preparation for adulthood. Casey Family Services, The Casey Center for Effective Child Welfare Practice. Accessed via http:// www.caseyfamilyservices.org/pdfs/casey_permanency_0505.pdf

Harbert, A.S., Finnegan, D., \& Tyler, N. (1997). Service integration: Something old and something new. Administration in Social Work, 21(3/4), 9-29.

Kelley, T. M. (2003). Health realization: A principle-based psychology of positive youth development. Child \& Youth Care Forum, 32(1), 47-72.

Kemp, S., \& Bodony, J. (2000). Infants who stay in foster care: Child characteristics and permanency outcomes of legally free children first placed as infants. Child and Family Social Work, 5, 95-106.

Landsman, M.J. (2001). Commitment in public child welfare. Social Service Review, 75(3), 386-419.

Landsman, M.J., Tyler, M., Black, J., Malone, K., \& Groza, V. (1999). Evaluation of the permanency for teens project: Final report. Iowa City, Iowa: University of Iowa.

Lofquist, W., \& Miller, M. (1989). Inventory of adult attitudes and behavior: An Instrument for examining the nature of adult/youth relationships. Tuscon, AZ: Associates for Youth Development, Inc.

Mallon, G.P (1998). After care, then what? Outcomes from a study of an independent living program. Child Welfare, 77, 61-78.

McMillen, J.C., \& Tucker, J. (1999). The status of older adolescents at exit from outof-home care. Child Welfare, 78(3), 339-360.

Mor Barak, M.E., Levin, A., Nissly, J.A., \& Lane, C.J. (2006). Why do they leave? Modeling child welfare workers' turnover intentions. Children and Youth Services Review, 28(5), 548-577.

Morgan, G. (1995). Collaborative models of service integration. Child Welfare, 74(6), 1329-1342. 
National Center for Lesbian Rights (2005). Breaking the silence: Lesbian, gay, bisexual, transgender, and queer foster youth tell their stories. San Francisco, CA.

Nicholson, H. J., Collins, C., \& Holmer, H. (2004). Youth as people: The protective aspects of youth development in after-school settings. Annals of the American Academy of Political and Social Science, 591, 13-24.

Nollan, K., Pecora, P., Lewy, J., et al. (2000). How are the children doing part II? Assessing youth outcomes in family foster care. Seattle: Casey Family Programs, p. 9.

Rycraft, J.R. (1994). The party isn't over: The agency role in the retention of public child welfare caseworkers. Social Work, 37(5), 454-458.

Urwin, C., \& Haynes, D.T. (1998). A reflexive model for collaboration: Empowering partnerships through focus groups. Administration in Social Work, 22(2), 23-39.

U.S. Department of Health and Human Services, Administration for Children and Families, Administration on Children, Youth and Families, Children's Bureau, www.acf.hhs.gov/programs/cb Preliminary Estimates for FY 2006 as of January 2008 (14).

Walter, U.M., \& Petr, C.G. (2000). A template for family-centered interagency collaboration. Families in Society, 81(5), 494-503.

Wattenberg, E., Kelley, M., \& Kim, H. (2001). When rehabilitation ideal fails: A study of parental rights termination. Child Welfare, 80(4), 4.

Westat Inc. (1991). A national evaluation of the Title IV-E foster care independent living programs for youth-Phase 2: Final report. Washington, DC: Author. 